\title{
Mechanochemical synthesis of intermetallic compounds in the system gallium - ruthenium
}

\author{
T.F. Grigoreva ${ }^{a^{*}} \mathbb{D}$, E.A. Pavlov ${ }^{\mathrm{b}}$, P.A. Vitiaz ${ }^{\mathrm{c}}$, N.Z. Lyakhov ${ }^{\mathrm{a}}$
}

a: Institute of Solid State Chemistry and Mechanochemistry SB RAS, Kutateladze St. 18, Novosibirsk, 630090, Russia

b: JSC “Zelenyj Gorod”, 6o let Oktyabrya St. 126, Krasnoyarsk, 660079, Russia

c: Joint Institute of Mechanical Engineering of the National Academy of Sciences of Belarus, Akademicheskaya St. 12, Minsk, 220072, Belarus

* Corresponding author: corresponding_grig@solid.nsc.ru

This article belongs to the PCEE-2020 Special Issue.

(C) 2021, The Authors. This article is published in open access form under the terms and conditions of the Creative Commons Attribution (CC BY) license (http://creativecommons.org/licenses/by/4.o/).

\section{Abstract}

The interaction of a solid inert metal $\mathrm{Ru}$ with liquid active metal $\mathrm{Ga}$ during mechanical activation in a high-energy planetary ball mill was studied using the X-ray diffraction and the high resolution scanning electron microscopy with energy dispersive X-ray microanalyses. This paper considers mechanical activation effects on formation of intermetallic compounds $\mathrm{Ga}_{\mathrm{x}} \mathrm{Ru}_{\mathrm{y}}$ and their solubility in concentrated acids. Gallium is a surface-active substance with respect to Ruthenium. Under intensive mechanical treatment, liquid Gallium penetrates into grain boundaries of polycrystalline Ruthenium particles and sharply reduces their strength. Because of severe mechanical deformation, an intensive increase of contact surface between solid and liquid metals observed, which a place of rapid formation of intermetallic compounds. This processing leads to high reactive products of mechanical activation of $\mathrm{Ga}+\mathrm{Ru}$. Their interaction with a mixed concentrated hydrochloric and nitric acid allows Ruthenium $(\sim 37 \%)$ to pass into an acidic solution, forming complex compounds of the $\mathrm{H}_{\mathrm{x}} \mathrm{RuCl}_{\mathrm{y}}$ type $\left(\mathrm{H}_{2} \mathrm{RuCl}_{6}\right)$.

\section{Keywords}

mechanochemical synthesis

intermetallics

gallium

ruthenium

complex compounds

of ruthenium

Received: 28.12 .2020

Revised: 05.02.2021

Accepted: 05.02.2021

Available online: 08.02.2021

\section{Introduction}

Ruthenium is the most chemically and heat-resistant metal of the platinum group metals, so $\mathrm{Ru}$ is applied as alloys additive for manufacturing turbine blades of jet engines, high temperature parts of missiles, equipment for aircraft devices [1].

A promising area for using Ruthenium is solar energy. The ability of Ruthenium to bind catalytically atmospheric nitrogen at room temperature is also unique. The alloys of Ruthenium with Platinum and Iridium are used for manufacturing dies in the production of glass fibers and viscose.

An efficient approach to obtain ultra-fine high purity metals can be their dissolution in acids with formation of ammonium salts and subsequent reduction. For Ruthenium, there is a problem with the dissolution, because this metal does not interact even with highly concentrated acids. It is known that intermetallic compounds (IMC) and alloys dissolve faster than their constituent inert metals, especially in case of well-developed interfacial or inter- granular surface $[2,3]$. The conversion of an inert metal into a soluble form becomes possible when one of the components of the IMC dissolves easily. This effect is much more pronounced for ultra-dispersed IMC, and mechanochemical synthesis is one of the most promising techniques for their production.

In systems with interacting solid and liquid metals, the adsorption-active properties of the liquid metal with respect to most hard solid metals were verified $[4,5]$. Penetration of liquid metal along the grain boundaries sharply reduces the strength characteristics of the latter [6-9]. The work of destruction of polycrystalline metal in contact with the melt reduces by hundreds of times, which provides a high rate of formation of a "fresh" (native) surface of a solid metal. Due to the high wettability of the solid surface with liquid metal, the contact surface of the solidliquid metal can reproduce itself permanently, and IMC synthesis continues [8,10-12]. From this point of view, it is very likely that the inert Ruthenium should chemically interact with the active liquid Gallium, since it is known 
that $\mathrm{Ga}_{3} \mathrm{Ru}, \mathrm{Ga}_{2} \mathrm{Ru}$, and $\mathrm{GaRu}$ are able to form in the Ga$\mathrm{Ru}$ system at high temperature and pressure. The full equilibrium state diagram of the $\mathrm{Ga}-\mathrm{Ru}$ system has not been evaluated yet [13]. The presence of several intermetallic compounds in the $\mathrm{Ga}-\mathrm{Ru}$ system is probably due to the negative enthalpy of mixing. In a pair of solid $\mathrm{Ru}-$ liquid $\mathrm{Ga}$ (with melting temperature $29.8{ }^{\circ} \mathrm{C}$ ), the mechanochemical synthesis is possible thanks to formation of large contact surface $\mathrm{Ru} / \mathrm{Ga}$. Gallium is highly soluble in acidic solutions [14]. This makes it possible to leach $\mathrm{Ga}$ from intermetallic compounds $\mathrm{Ga}_{\mathrm{x}} \mathrm{Ru}_{\mathrm{y}}$ obtained mechanochemically, thus increasing the ability for Ruthenium to dissolve in concentrated acids.

Analysis of scientific literature data shows that there are no studies of mechanical interaction of platinum satellite metals ( $\mathrm{Ir}, \mathrm{Ru}, \mathrm{Rh}$ ) with liquid Gallium, so this study is relevant.

The aim of this is work to study the process of mechanochemical synthesis of intermetallic compounds in the $\mathrm{Ga}-\mathrm{Ru}$ system, as well as the acid separation of Gallium from synthesized IMC in order to convert Ruthenium into a soluble form.

\section{Experimental}

Liquid Gallium and Ruthenium powder were used to prepare the intermetallics $\mathrm{Ga}_{\mathrm{x}} \mathrm{Ru}_{\mathrm{y}}$.

Mechanochemical synthesis of intermetallic compounds in the inert solid metal (Ruthenium) - active liquid metal (Gallium) system was carried out in a high-energy planetary ball mill AGO-2. The volume of milling drums was $250 \mathrm{~cm}^{3}$. Steel balls of $5 \mathrm{~mm}$ diameter with total mass $200 \mathrm{~g}$ were used to achieve the ball-to-powder ratio 20:1. The rotation speed of the drums around the common axis was 1000 rpm. During milling, drums and balls were cooled with water [15].

To determine the degree of dissolution of the initial Gallium and Ruthenium, mechanochemically synthesized intermetallic compounds $\mathrm{Ga}_{\mathrm{x}} \mathrm{Ru}_{\mathrm{y}}$, they were treated with a mixture of concentrated acids $\left(60 \mathrm{ml} \mathrm{HCl}+20 \mathrm{ml} \mathrm{HNO}_{3}\right)$, for three hours, at a temperature of $75^{\circ} \mathrm{C}$. Samples of $1 \mathrm{~g}$ each were weighed directly in $400 \mathrm{ml}$ glasses with analytical Mettler Toledo RT 503 balance (weighing accuracy of $0.001 \mathrm{~g}$ ). Separation of insoluble sediments from solutions was carried out in several stages using paper filters with a pore size of $2-3 \mu \mathrm{m}$. Glass measuring cylinders were used to determine the volume of filtrate and washing water.

$\mathrm{X}$-ray phase analysis of the powders was carried out using an XPERT-PRO diffractometer ( $\mathrm{Cu} \mathrm{K} \alpha 1$ radiation, wavelength $=1.54051 \AA$, the $2 \theta$ angle range from $3.0131^{\circ}$ to $90.91^{\circ}$, step $\Delta 2 \theta=0.001^{\circ}$ ).

Morphological characteristics and elemental composition of the initial Ruthenium powder, as well as mechanochemically synthesized $\mathrm{Ga}_{\mathrm{x}} \mathrm{Ru}_{\mathrm{y}}$ intermetallides and $\mathrm{Ga}_{\mathrm{x}} \mathrm{Ru}_{\mathrm{y}} / \mathrm{Ru}$ composites, before and after treatment with a mixture of concentrated acids, were obtained on a scan- ning electron microscope JEOL $6601 \mathrm{LV}$ (accelerating voltage $20 \mathrm{kV}$, magnification up to $\times 10000$ ) with an energydispersive X-ray microanalyzer (EDXA). The error of the elemental content analysis on the EDXA was 0.2-0.3 mass. \%.

\section{Results and Discussion}

According to scanning electron microscopy, the initial Ruthenium powder consists of primary particles with size within 1-3 $\mu \mathrm{m}$; round shaped particles form porous agglomerates with the size in between 5 to $20 \mu \mathrm{m}$ (Fig. 1). According to the results of EDXA, the Ru content is $100 \%$.

According to $[16,17]$, for interacting metals an intermetallic compound with the maximum content of fusible metal is first formed on the contact surface. Accordingly, in the interacting Ga-Ru system, some phases with the highest Gallium content must be formed first, and when Gallium is totally spent the mechanochemical interaction of the IMC with Ru will start forming intermetallic phases with a lower Gallium content (GaRu) [18].

It can be expected that at the initial stage of the mechanical activation of the $\mathrm{Ga}+\mathrm{Ru}$ mixture the bulk Gallium will cover the Ruthenium particles with an extremely thin layer, forming $\mathrm{Ga}_{3} \mathrm{Ru}$ or $\mathrm{Ga}_{2} \mathrm{Ru}$ on the contact surface of the compound, since, according to Miedema calculations, the mixing enthalpy is about $-8 \mathrm{~kJ} / \mathrm{mol}$ [19-21]. These IMCs will further interact with Ruthenium to form GaRu.

By means of X-ray phase analysis, the products of the chemical interaction of ruthenium with gallium (with molar ratio $\mathrm{Ga}: \mathrm{Ru}=1: 1$ ) are detected only after 2 minutes of mechanical activation. (Fig. 2, curve 1).

A noticeable amount of this phase is formed in the mixture when activated for $14 \mathrm{~min}$ (Fig. 2, curve 2), at the same time a weak diffraction peak appears on the X-ray pattern, which may be due to the formation of GaRu as a result of the interaction of $\mathrm{Ga}_{2} \mathrm{Ru}$ with Ruthenium. As the activation time increases up to 20,34 , and $62 \mathrm{~min}$, the newly formed $\mathrm{Ga}_{2} \mathrm{Ru}$ is consumed to form $\mathrm{GaRu}$, resulting in the increasing diffraction peak intensities of secondary phase (Fig. 2, curves 3-5).

Electron microscopic studies showed the small particles of $\sim 0.2-0.5 \mu \mathrm{m}$ after 2 min of activation (Fig. 3, photo a). After activation for $14 \mathrm{~min}$, the sample contains the

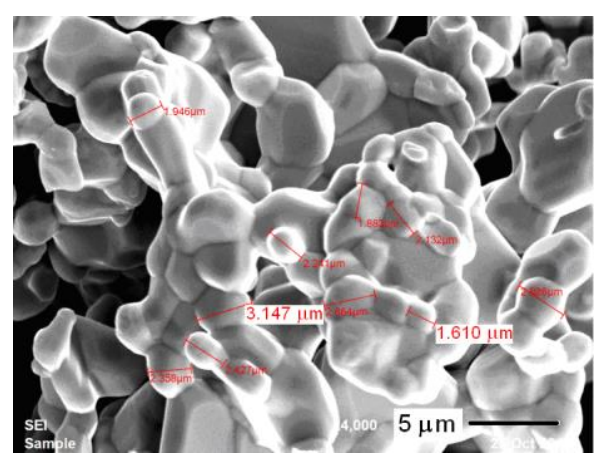

Fig. 1 SEM image and particle size of the as received $\mathrm{Ru}$ powder $(\times 4000)$ 
small particles of $\sim 0.2-0.5 \mu \mathrm{m}$ and agglomerates of different types: dense $\sim 0.5-5 \mu \mathrm{m}$ and porous (loose) - up to 10 $\mu \mathrm{m}$ (Fig. 3, photo $b$ ). In the sample activated $34 \mathrm{~min}$, there are significantly fewer small particles of $\sim 0.2-0.5 \mu \mathrm{m}$, and much more of agglomerates with a wide size distribution from $\sim 0.5$ to $5 \mu \mathrm{m}$ (Fig. 3, photo $c$ ).

According to the EDXA, the iron content in the samples increases from $0.5-0.7$ to 6-8 wt. \% due to the wear contaminations from balls and drums, depending on time of mechanical activation.

Preliminary experiments showed the starting Gallium totally dissolved in a mixture of concentrated acids within 40 min. The highly dispersed Ruthenium powder does not dissolve under the above conditions, remaining the same morphological features as the original Ruthenium (Figs. 1 and 4).

It was found that the amount of Ruthenium in a mixture of concentrated acids increases with the increase in the content of intermetallic compounds in mechanocomposites obtained. So, after 20 min of mechanical activation it was 27.09 wt.\%, after $34 \mathrm{~min}$ the value increased to $36.78 \mathrm{wt}$. \%. The insoluble precipitate after MA for $34 \mathrm{~min}$ is an ultrafine powder with an average particle size of less than $0.5-0.6 \mu \mathrm{m}$ (Fig. 5).

We can expect that Ruthenium is oxidized to form a complex acid $\mathrm{H}_{\mathrm{x}} \mathrm{RuCl}_{\mathrm{y}}$ in the course of transition from a mechanocomposite to an acidic solution.

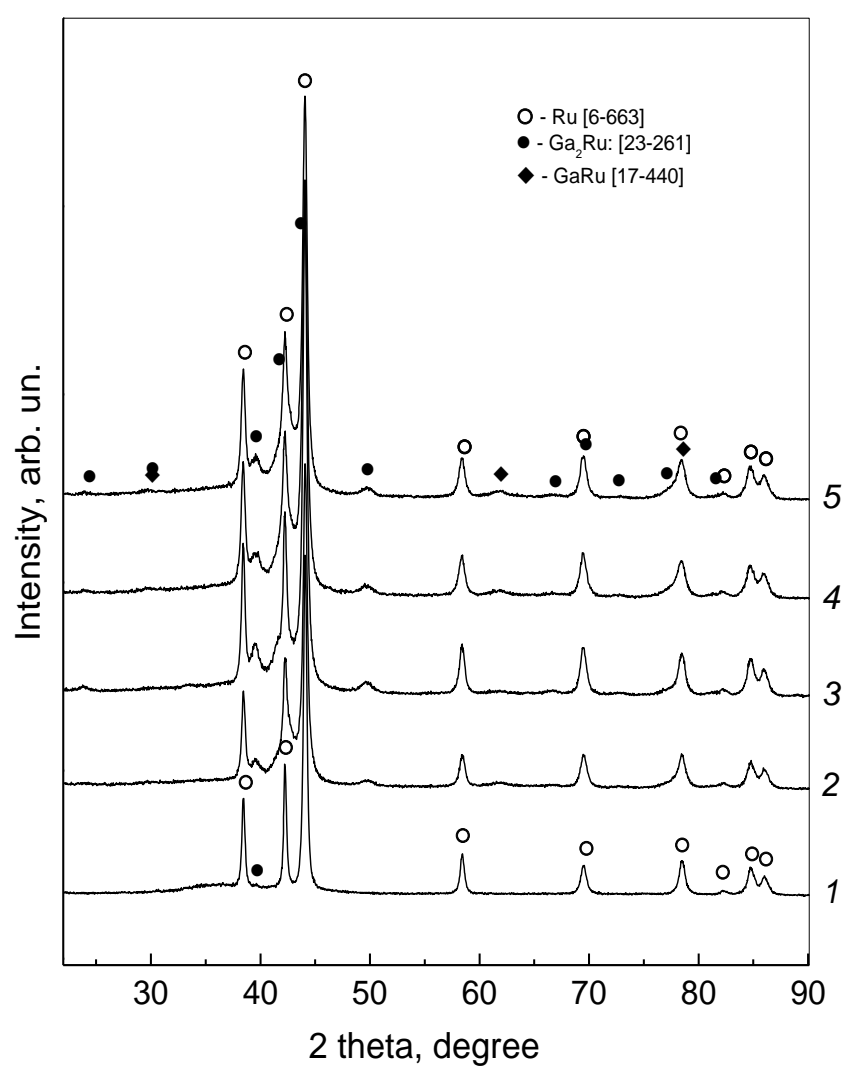

Fig. 2 X-ray patterns of the products of mechanochemical interaction of $\mathrm{Ru}$ with $\mathrm{Ga}$ in depending on the duration of mechanical activation (min): 2 (1), 14 (2), 20 (3), 34 (4), 62 (5).

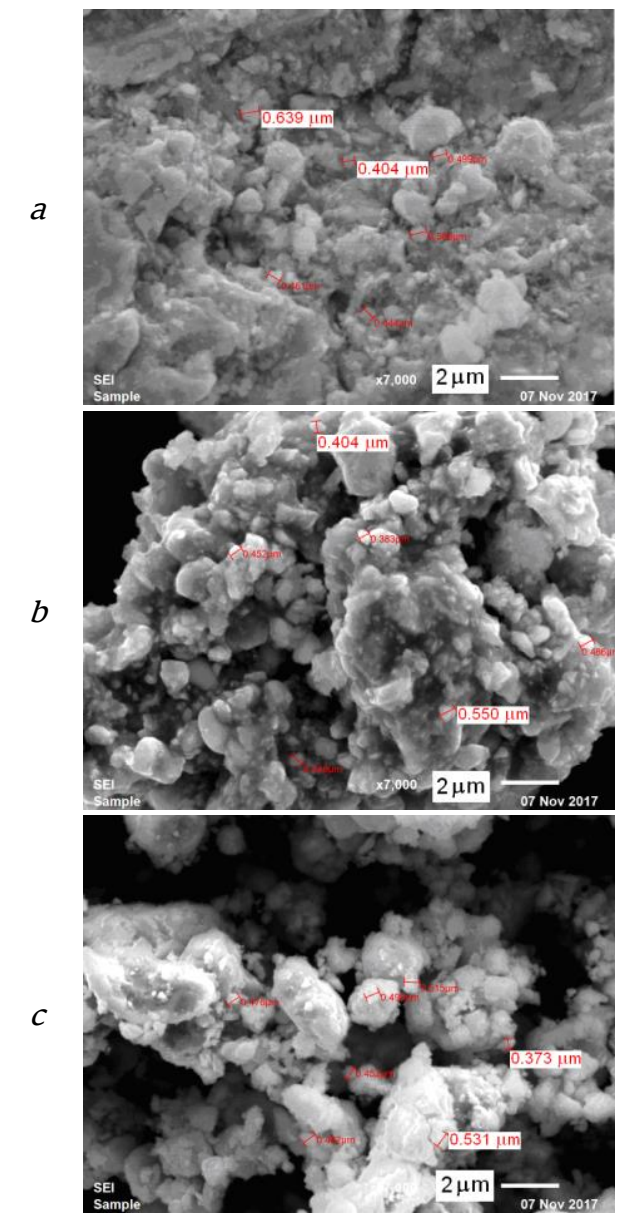

Fig. 3 SEM images of the products of mechanochemical interaction of $\mathrm{Ru}$ with $\mathrm{Ga}$ depending on the duration of mechanical activation (min): $2(a), 14(b), 34(c)$.

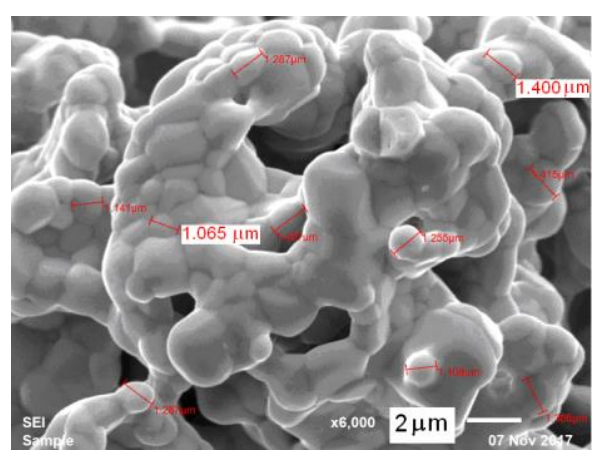

Fig. 4 SEM image of the insoluble precipitate particles of the original $\mathrm{Ru}$ powder after treatment with acid mixture $(\times 6000)$

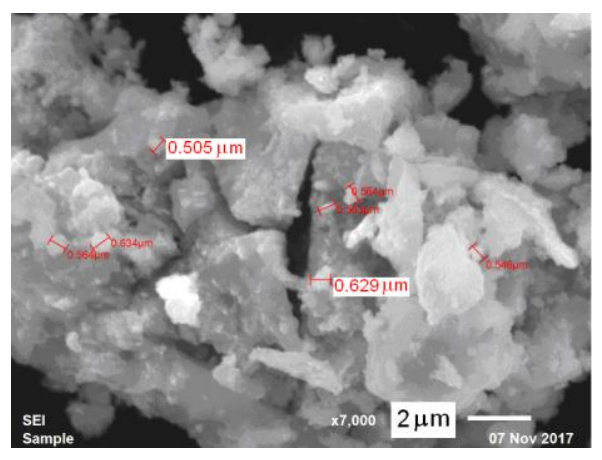

Fig. 5 SEM image of the insoluble precipitate obtained from $\mathrm{Ru}-$ Ga intermetallic (MA for $34 \mathrm{~min}$ ) after treatment with concentrated acid mixture $(\times 7000)$ 


\section{Conclusions}

For metallic systems with Platinum satellite metals, the example of the $\mathrm{Ru}-\mathrm{Ga}$ system shows that the problem of converting chemically inert Ruthenium into a soluble form can be solved by mechanochemical synthesis of intermetallic compounds $\mathrm{Ru}$ with liquid $\mathrm{Ga}$ and subsequent extraction of Gallium into acidic solutions. Being a surface-active substance in relation to Ruthenium, liquid Gallium penetrates into grain boundaries of polycrystalline Ruthenium particles, which strongly reduces their strength. There is an increase in the contact surface between solid Ruthenium and liquid Gallium, which leads to the active formation of intermetallic compounds. It is shown that chemically active Gallium passes from intermetallic to solution when treated with a mixture of concentrated acids $\mathrm{HCl}$ and $\mathrm{HNO}_{3}$, while the reactivity of Ruthenium increases and more than $36.7 \%$ of Ruthenium passes into a soluble form.

\section{Acknowledgments}

The research was carried out within the state assignment to ISSCM SB RAS (project No. 0237-2021-0002).

\section{References}

1. Emsley J. Ruthenium. Nature's Building Blocks: An A-Z Guide to the Elements. Oxford, England, UK: Oxford University Press; 2003. p. 368-70.

2. Ginzburg SI, Ezerskaya NA, Prokof'eva IV, Fedorenko NV, Shlenskaya VI, Bel'skiy NK. Analiticheskaya khimiya platinovykh metallov [Analytical chemistry of Platinum metals]. Alimarin IP, editor. Moscow: Nauka; 1972. 616 p. Russian.

3. Kakovskiy IK, Potashnikov YuM. Kinetika rastvoreniya [Kinetics of dissolution]. Moscow: Metallurgiya; 1975. p. 12638. Russian.

4. Knizhnik GS. Structural changes in a solid metal in contact with a liquid. Poverkhnost. Fizika, khimiya, mekhanika. 1984;4:121-33.

5. Gapeev AK, Kulakov VI, Zver'kov SA, Sokolovskaya EM. Features of reactive diffusion in the Nb-Ga system. Vesti Moskovskogo Universiteta. Khimiya. 1978;4:470-2.

6. Hugo RC, Hoagland R. In situ TEM observation of aluminum embrittlement by liquid gallium. Scripta Mater. 1998;38:523-9. doi:10.1016/S1359-6462(97)00464-8
7. Hugo RC, Hoagland R. Gallium penetration of aluminum: in situ TEM observation at the penetration front. Scripta Mater. 1999;41:1341-6. doi:10.1016/S1359-6462(99)00293-6

8. Trenikhin MV, Bubnov AV, Kozlov AG, Nizovskii AI, Duplyakin VK. The penetration of indium-gallium melt components into aluminum. Russ J Phys Chem. 2006;80:1110-4. doi:10.1134/So036024406070193.

9. Trenikhin MV, Bubnov AV, Nizovskii AI, Duplyakin VK. Chemical interaction of the In-Ga eutectic with $\mathrm{Al}$ and Al-base alloys. Inorganic Materials. 2006;42:256-6o. doi:10.1134/S0020168506030083

10. Yasuda H, Mori H. Formation of compound semiconductor clusters by spontaneous alloying. Mater Sci Eng. 1996;A217/218:249-52. doi:10.1016/So921-5093(96)10360-9

11. Mori H, Yasuda H. Spontaneous alloying in nanometer-sized ultra-fine particles. Mater Sci Forum. 1998;269-272:327-32. doi:10.1142/S0218625X96002096

12. Shimizu Y, Ikeda KS, Sawada S. Spontaneous alloying in binary metal microclustres. A molecular dynamic study. Phys Rev B. 2001;64(7):075412. doi:10.1103/PhysRevB.64.075412

13. Lyakishev NP, editor. Diagrammy sostoyaniya dvoinykh metallicheskikh system: Spravochnik, tom 2 [Phase diagrams of binary metallic systems: A Handbook, vol. 2]. Moscow: Mashinostroenie; 1997. 1024 p. Russian.

14. Ivanova RV. Khimiya i tekhnologiya galliya [Chemistry and technology of gallium]. Moscow: Metallurgiya; 1973. 392 p. Russian.

15. Avvakumov EG. Mekhanicheskie metody aktivatsii khimicheskikh protsessov [Mechanical methods of activation of chemical processes]. Novosibirsk: Nauka; 1986. 302 p. Russian.

16. Savitskiy AP. Zhidkofaznoe spekanie sistem s vzaimodeystvuyushchimi komponentami [Liquid-phase sintering of systems with interacting components]. Novosibirsk: Nauka. Sib. otd.; 1991. 180 p. Russian.

17. Summ BD, Goryunov YuV. Fiziko-khimicheskie osnovy smachivaniya i rastekaniya [Physico-chemical fundamentals of wetting and spreading]. Moscow: Khimiya; 1976. 231 p. Russian.

18. Yatsenko SP. Galliy: Vzaimodeystvie s metallami [Gallium: Interaction with metals]. Moscow: Nauka; 1974. 218 p. Russian.

19. Miedema AR. On the heat of formation of solid alloys (II). J Less-Common Met. 1976;46:67-83. doi:10.1016/0022-5088(76)90180-6

20. Miedema AR, de Chatel PF, de Boer FR. Cohesion in alloys fundamentals of a semi-empirical model. Physica B. 1980;100:1-28. doi:10.1016/0378-4363(80)90054-6

21. Bakker H. Miedema's semi-empirical model for estimating enthalpies in alloys. Mater Sci Briefings. 1988;1:1-80. 